with urethane were asphyxiated by occlusion of the trachea: the respirations became slower, and later deeper as well, and finally ceased : about a minute later a series of gasps occurred, which were usually ineffective in restoring the circulation (the trachea having been opened) unless the heart was also beating. The blood pressure fell when respiration ceased, and the heart gradually stopped.

Manual pressure on the chest may now cause recovery, both by renewing the air in the lungs and by pumping blood through the heart; artificial ventilation of the lungs alone may fail. The blood pressure may rapidly rise to an abnormal height before settling to the normal level, probably due to passage of adrenaline in the stagnant venous blood through the heart and arteries. The injection of adrenaline into the heart, especially the myocardium, will restore the beat to normal if the organ is beating feebly, or will arouse it again if given fairly soon after stoppage, together with inflation of the lungs. At the same time, it constricts the arteries and raises the blood pressure to its normal level or even higher. With restoration of the circulation, the breathing also returns, and though at first slow and deep, gradually becomes normal in character and rate. The injection of adrenaline into the heart, together with artificial respiration, will only be successful in the human being provided the breathing and circulation have not been too long in abeyance; ten minutes is probably the limit in ordinary circumstances.

The manual method of artificial respiration is inconvenient and difficult to apply successfully over a prolonged period of time; P. Drinker and L. A. Shaw have invented a mechanical respirator for use in the respiratory paralysis of anterior poliomyelitis in children and in cases of respiratory failure due to carbon monoxide poisoning, electrocution, drowning, etc. (J. Franklin Inst., vol. 213, p. $355 ; 1932$ ). The patient is placed, except for his head, in a closed chamber ; the neck is encircled by an air-tight flexible rubber collar. Air is rhythmically pumped from the chamber, producing inhalation in the patient; exhalation occurs when the air pressure returns to normal. The patient's respiration is completely under the control of the machine when the negative pressure is $7 \mathrm{~cm}$. of water. The apparatus has been found so successful that more than 150 are now in use in the United States and Canada. It is of interest to note that the optimum diameters of the rubber collar and head hole in the lid were obtained by plotting frequency curves from manufacturers' sales of different sizes of collars and hats.

\title{
Cosmic Radiation
}

[N a paper presented at the recent International Electrical Congress held at Paris, Prof. R. A. Millikan summarised in a convincing manner his views concerning the nature and origin of the penetrating cosmic radiation. The idea that they are neutrons, although it would combine the advantages of particles with failure to be deflected in the magnetic field of the earth, he considers unnecessary and not superior to the photon hypothesis. Commenting on the experiments which have been made to find if there is any preferential direction in which they enter the air, Prof. Millikan takes the view that there is no evidence that they are other than isotropic; this is in accord with his interpretation of their absorption curve, according to which the cosmic rays arise from processes involving the agglomeration of hydrogen nuclei for, probably, a very long time until they condense catastrophically to form a new nuclear type, which could scarcely occur where the temperature and pressure were not extremely low, as in interstellar space.

This paper contains some details of the experiments which have been made by Anderson in the Norman Bridge Laboratory in California, with a Wilson ex- pansion chamber. The main aim of these was to deffect the products of the interaction of the rays with matter in a magnetic field, but many interesting subsidiary observations have been made.

The cosmic rays appear to be absorbed largely by nuclei, in general accord with the supposition that they arise in nuclear processes, but destroying the validity of the immediate application of the Klein. Nishina absorption formula, which assumes interaction with the extra-nuclear electrons. About thirty good trails have been photographed. Eleven show a proton with an energy of the order of some $10^{8}$ electron-volts, two an electron of similar energy, three protons of between sixteen and forty million volts, five electron trails of about ten million volts, and the remainder particles of greater energy than $5 \times 10^{8}$ volts. The reality of the latter would not be in agreement with Prof. Millikan's atom-building postulates, the energy being excessive, but there is some doubt if they are authentic, as the trails show a number of sudden small deflections which are difficult to reconcile with the transit of such energetic particles. In seventeen per cent of the encounters with nuclei, the latter suffered disintegration.

\section{International Conference on Radio Communication}

RADIO engineers are looking forward anxiously to the international conference in Madrid on radio communication, which begins in September. In the Wireless World for Aug. 19 and 26, Noel Ashbridge, chief engineer to the British Broadcasting Company, states some of the problems of which a solution will have to be found. He confines himself to the broadcasting problem, and discusses first the problem of separating the frequencies and consequently the wavelengths of the stations in Europe.

The existing agreement, known as the Prague plan, was put into operation by a large majority of the signatories in June 1929. It was decided that, so far as wave-lengths between 200 metres and 545 metres are concerned, the minimum separation between stations should be 9 kilocycles. This number was not selected on technical grounds but because it was the only hope of getting a general agreement. For the first year after the agreement the arrangement worked very well, only a few people who had signed the agreement failing to observe it in practice. During this year there were only a few stations which worked with a higher power than $15 \mathrm{kw}$.

Serious trouble started in November 1930, when Mühlacker, a high-power station, operated with a frequency adjoining that of London Regional. The result was immediate and severe jamming after dark on the London programme. The condition of affairs was very bad, because two years ago ordinary receivers were not nearly so selective as they are now.

No. 3279, Vor. 130] 
The German engineers showed how the interference in the receiver could be cut out altogether, but the quality of the speech delivered was seriously affected. The solution adopted was to increase the separation between Mühlacker and London to 11 kilocycles. It is proved that if there is to be freedom from interference at the limit of the service area, the reproduction of frequencies of more than about 4000 cycles cannot be obtained and so the reproduction is not good.

It has been said that the response of a loud-speaker up to about 4000 cycles per second is sufficient for most practical purposes, and that, therefore, the interference problem does not now exist. Mr. Ashbridge states that, for really good quality reception, frequencies up to 7000 should be reproduced. A gramophone record reproduces something appreciable up to and a little beyond 5000 cycles, and yet the lack of the upper frequencies is quite noticeable to the critical ear. In future, this will doubtless be much improved. It would be a pity if broadcasting were permanently made inferior to the gramophone. Theoretically, the separation of broadcasting stations should be governed by the band of audio frequencies which it is necessary to cover in order to give full effect to the programmes.

If it is agreed to keep the 9 kilocycle separation, then those living in areas of high field-strength will get good quality service, whilst the others must have the higher frequencies eut off. If it were agreed to have a wider separation, then it would be necessary to reduce the number of stations in Europe as a whole. No one has ever pressed for a larger separation than 11 kilocycles, and experiments show that the range of reproduction can by this means be increased fifty per cent. The question of the limitation of the power of the various stations is a very difficult one. If they are too weak, we have 'fading'; if too strong, we cannot get the higher frequencies. It is difficult to say which is the more objectionable.

\section{Calendar of Geographical Exploration}

\section{Sept. 7, 1298.-Marco Polo}

According to Ramusio, Marco Polo was taken prisoner by the Genoese in a battle off Curzola in Dalmatia. Whether this was the exact date or not, it is at any rate certain that in 1298 Marco Polo was imprisoned in Genoa and that he there dictated his narrative to his fellow-prisoner, Rustician of Pisa. Marco Polo came of a family of Venetian traders; his father and uncle had visited the court of the Grand Khan, near Peking, on a journey which began in 1255. After their return, they again set out, taking Marco with them, in 1271. They travelled from Acre through Armenia, passed through Bagdad and Basra to Ormuz, turned inland and crossed Persia to Balkh. Thence they travelled across the Pamirs to Kashgar, went through Yarkand and Khotan to the south of Lob Nor, crossed the difficult Ordos desert and reached Peking. They remained in China for seventeen years, and returned by the sea route, a voyage which no European had ever before made from a Chinese port. Of all medieval travellers, Marco Polo is justly the most famous. To the unique opportunities given him by his long journeys and his prolonged stay in China he brought a vivid personality, keen and alert to notice everything of interest in his surroundings. In his narrative he shows a discriminating selection of the crucial facts of the geography and social and economic life of each of the many regions through which he passed. Thus, though six hundred years and more have passed since his book was written, it still holds readers by its charm and insight.

\section{Sept. 7, 1787.--La Pérouse Strait}

La Pérouse put in at Petropavlovisk in Kamchatka and thence sent Lesseps overland with the journals, notes, plans, and maps recording the work of his expedition. This foresight saved these most important observations from destruction, for after a letter of Feb. 7, 1788, from Australia, nothing more was heard of him until 1826, when Capt. Dillon found the wreckage of his ships on Vanikoro, an island to the north of the New Hebrides. La Pérouse sailed on Aug. 1, 1785, from Brest, to try to discover the north-west passage from the Pacific side. He reached. Mount St. Elias, Alaska, on June 23, 1786, visited the Hawaii group, and discovered Necker Island. Thence he passed to the coasts of Japan, Korea, and 'Chinese Tartary', and discovered the strait between Sakhalin and the northern island of Japan which bears his name.

\section{Sept. 7, 1837.-Adélie Land}

The great French explorer, Dumont d'Urville, sailed from Toulon with two vessels, the Astrolabe and the Zelée, to search for land in the south polar regions. $\mathrm{He}$ attempted to follow Weddell's track, but was held up by pack ice and returned to make investigations in the Pacific. On Jan. I, 1840, the vessels left Hobart, and discovered Adélie Land later in the month. D'Urville's work, both on this voyage and on a former one in 1826-29, added much to our knowledge of the geography of the Pacific, especially of the Fiji Islands, the Carolines, and the Moluccas. He also helped to chart more accurately the coasts of New Guinea and New Zealand. During his 1826-29 voyage he found evidence of the wreck of La Pérouse's vessel, which had disappeared in 1788, on the island of Vanikoro, one of the Santa Cruz group. On a voyage in the eastern Mediterranean he visited the island of Melos, and saw an old Greek statue which had just been unearthed. His keen appreciation of its beauty resulted in the acquisition by the Louvre of the famous Venus de Milo. This artistic sense led him to take the French artist Goupil with him to the antarctic ; the resulting illustrations of his journal added much to its descriptive value, as well as to its beauty.

\section{Societies and Academies}

PARIS

Academy of Sciences, July 18 (vol. 195, pp. 193-292). - L. Blaringhem: Reappearance of fertility in a new variety of wild foxglove (Digitalis purpurea).-Charles Achard, Augustin Boutaric, and Maurice Doladilhe: The dilution of horse serum in electrolytic solutions. In an earlier paper it has been shown that by diluting 1 c.c. of serum to a volume $l$ and measuring the optical density of the solution $(h)$, then $l h$ increases at first, passes through a maximum, and decreases to a limiting value. This work has now been extended to solutions containing salts.-Emile Guyénot, W. Bartschi, and Mlle. K. Ponse: The production of the yellow bodies studied by the method of transplantation of the ovary on to male guinea-pigs.-J. Schauder : The problem of Dirichlet generalised for non-linear equations of the elliptic type.-J. Ottenheimer : The displacement of water and the nature of the waves recorded in submarine explosions.-D. Riabouchinsky : Experimental researches on the formation of cavitations.-Hensi Mineur, Miles. Renée Canavaggia and Marie-Louise Fribourg: The correlation between the velocity of the star mass and their distance in the galactic plane.--René Audubert: The Debye-Hückel theory and electrophoresis.-M. Pauthenier, Mme. M. Moreau-Hanot, and R. Guillien : The charge of small 